\begin{tabular}{lc|l}
\hline Bentham OPEN & The Open Nursing Journal & $\begin{array}{l}\text { The } \\
\text { Open Nursing } \\
\text { lournal }\end{array}$ \\
\hline CrossMark & Content list available at: www.benthamopen.com/TONURSJ/ & DOI: $10.2174 / 1874434601610010026$ \\
\hline
\end{tabular}

\title{
What is Health and What is Important for its Achievement? A Qualitative Study on Adolescent Boys' Perceptions and Experiences of Health
}

\author{
Eva Randel1 ${ }^{1,2, *}$, Lars Jerdén ${ }^{1,3}$, Ann Öhman ${ }^{1,4}$ and Renée Flacking ${ }^{2}$ \\ ${ }^{I}$ Department of Public Health and Clinical Medicine, Epidemiology and Global Health, Umeå University, 90187 \\ Umeå, Sweden \\ ${ }^{2}$ School of Education, Health and Social Studies, Dalarna University, 79188 Falun, Sweden \\ ${ }^{3}$ Center for Clinical Research Dalarna, Nissers väg 3, 79172 Falun, Sweden \\ ${ }^{4}$ Umeå Centre for Gender Studies (UCGS), Umeå University, 90187 Umeå, Sweden
}

Received: September 20, 2015

Revised: December 2, 2015

Accepted: December 15, 2015

\section{Abstract:}

Few qualitative studies have explored adolescent boys' perceptions of health.

Aim:

The aim of this study was therefore to explore how adolescent boys understand the concept of health and what they find important for its achievement

\section{Methods:}

Grounded theory was used as a method to analyse interviews with 33 adolescent boys aged 16 to 17 years attending three upper secondary schools in a relatively small town in Sweden.

\section{Results:}

There was a complexity in how health was perceived, experienced, dealt with, and valued. Although health on a conceptual level was described as 'holistic', health was experienced and dealt with in a more dualistic manner, one in which the boys were prone to differentiate between mind and body. Health was experienced as mainly emotional and relational, whereas the body had a subordinate value. The presence of positive emotions, experiencing self-esteem, balance in life, trustful relationships, and having a sense of belonging were important factors for health while the body was experienced as a tool to achieve health, as energy, and as a condition.

\section{Conclusion:}

Our findings indicate that young, masculine health is largely experienced through emotions and relationships and thus support theories on health as a social construction of interconnected processes.

Keywords: Adolescence, boys, grounded theory, health, qualitative, well-being.

\section{INTRODUCTION}

Adolescent boys are more reluctant to report ill-health and more likely to deny health problems than girls and they

\footnotetext{
* Address correspondence to this author at the School of Education, Health and Social Studies, Dalarna University, 79188 Falun, Sweden; Tel: +46 23 778118; +4670 4619120; E-mail: era@du.se
} 
regularly report a better subjective health than adolescent girls [1 - 3]. Furthermore, older adolescent boys' use of health care services is significantly lower compared with older adolescent girls [4]. On the other hand, they are much more likely than girls to engage in high-risk behaviour, have neuropsychiatric disorders/behavioural diagnoses (such as ADHD, autism, or conduct disorders), and have an increased risk of accidents, violence, and suicide [5 - 7]. Plausible explanations to these gender differences could be gender expectations for boys to be stoic and demonstrate masculinity $[8-10]$.

Although adolescents are in general physically healthy, there is a concern about the increasing rates of mental illhealth seen in the adolescent population in Sweden and other countries [11 - 13]. In Sweden, a substantial amount of research shows increasing mental health complaints, which can also be observed among adolescent boys [14, 15].

Health is a multidimensional concept, with definitions ranging from those taken from medical models based on absence of disease and disability to more holistic models of health [16 - 18]. Since ancient times, health has been regarded as a state of balance or equilibrium. Nordenfelt [19], for instance, argues for a holistic and action-oriented understanding of health in which there is a balance between what a person wants to do and can do in real life. The World Health Organisation's holistic definition of health - "a state of complete physical, mental, and social well-being and not merely the absence of disease or infirmity" - captures the subjective dimension of health [20]. Physical health refers to physical capabilities and functional levels, mental health to emotional health and well-being, and social health to how well a person gets along and interacts with other people [21 - 23].

Concerning health, there has been a historical assumption that body and mind are two separate entities. The concept of this dualism was developed in the $17^{\text {th }}$ century by Descartes, who argued that mind and body were two distinctive, but interacting entities [24]. Many health models reflect upon this body/mind division, as well as the distinction between mental and physical illness and between medical and therapeutic care [25, 26]. Estes [27] suggests that there is evidence of dualistic thinking taking place already in early childhood, i.e. children are able to distinguish between the internal and external and between mental and physical phenomena. Furthermore, it has been shown that those who hold dualistic beliefs are less likely to exercise and engage in health-enhancing behaviour [28]. Yet, most recent psychosocial theories of health reject dualism [29]. 'The lived body', how we experience and know the world through our bodies, represents the contrasting dialectic view of Merleau-Ponty [30], who stresses unity and emphasises the body as the embodiment of who we are [31]. The embodied perspective refers to a holistic view of health, suggesting that all parts of the body are integral and that meanings of health and illness impact on the person as a whole [32].

Studies exploring health in a youth context show that young people are prone to make a distinction between mental and physical aspects of health as well as in how these aspects are experienced and dealt with [3, 33]. Studies show also that mental health is sometimes associated with negative aspects (e.g., distress) or considered as an uncertain concept $[33,34]$. One study found that mental health problems in adolescents are seen as deviant, and consequently, the adolescents were hesitant out of fear to disclose emotions and behaviours that were not regarded as 'normal' [3]. Another study underscored the relational aspect of health in which health was described as a shared responsibility between adolescents and adults and mental health was seen as interactional rather than as an individual condition [17]. Several studies suggest that important determinants of mental health are the quality of relationships within the family and with friends and supportive adults, as well as having a positive self-concept [2, 34].

Still, little is known about older adolescent boys' experiences of health. Further, the knowledge base conceptualising health from a positive perspective is limited. Hence, there is a need to focus on factors conducive to health, inspired by the salutogenic approach [35]. Qualitative research will lead to the acquisition of knowledge on how adolescent boys view health and what they perceive as being important for their health, which may be useful in adolescent health promotion. The aim of this study was therefore to explore how adolescent boys understand the concept of health and what they find important for its achievement.

\section{METHODS}

\section{Setting and Sample}

The study was performed among 33 adolescent boys aged 16 to 17 years in a town with 56,000 inhabitants. In Sweden, the school system is composed of a nine-year compulsory school, starting at the age of seven, and a three-year non-compulsory upper secondary school, (ages 16-19 years). School education is provided free of charge, regardless whether it is municipally or independently run, and almost all pupils (99\%) continue to an upper secondary school. Upper secondary schools consist of national programmes (either vocational or academic) and introductory programmes 
that are preparatory for upper secondary schools for students who have not yet qualified.

To obtain maximum variation a purposive sampling procedure was adopted [36]. The participants were recruited from three upper secondary schools: one with mostly vocational programmes, one with mostly academic programmes, and one large school with a combination of vocational and academic programmes.

The first author contacted the schools via the headmasters and head teachers, visited classes, and gave a short oral presentation on the study, after which the adolescent boys were given the opportunity to ask questions. All boys were given written information about the study together with a consent form and a pre-stamped envelope. If they consented to being interviewed, they were instructed to sign the consent form and send it back to the first author. The criteria for inclusion were that the boys were 16 or 17 years of age and attending the first or second year of upper secondary school.

In total, 33 adolescent boys from three schools volunteered. Seventeen boys attended academic programmes, 12 attended vocational programmes and 4 were attending the introductory programme. The majority of the boys were born in Sweden but five were students with an immigrant background. The 33 participants represented varying socioeconomic backgrounds.

\section{Data Collection}

The interviews were performed by the first author between April 2011 and May 2012. Most of the interviews (29 out of 33) took place in conference rooms or private rooms at the schools. Two interviews were conducted at the home of the participants and two at the university where the first author is affiliated. All participants received a movie ticket in return for their participation.

The interviews, lasting between 35 and 70 minutes, were recorded. An interview guide was constructed and one test interview, not included in the study, was conducted to modify and generate questions. Throughout the study, the interview guide was slightly modified to find new relevant categories and deepen the concepts within the categories. The interviews were kept informal and conversational, with an aim to explore [37, 38]. The interview guide comprised both open and specific questions, including probe questions to deepen the descriptions. The interview questions were stated in an open-ended manner: "What does the word health mean to you?" "What affects your health? "What do you do in order to feel well?" "How do you deal with your health?"

\section{Ethical Consideration}

The study was approved by the Research Ethics Committee at Uppsala University, Dnr 2011/106 and ethical considerations were taken into account during entire process of the study. Children over 15 years of age are considered as autonomous decision makers in research processes according to the Swedish Act concerning the Ethical Review of Research Involving Humans (SFS 2003:460). Before turning on the tape recorder, all participants were asked to sign an informed consent and had an opportunity to ask questions related to the study. After each interview, the interviewer paid special attention to the participants' emotions and thoughts that had transmitted during the interview.

\section{Analysis}

A constructivist grounded theory approach according to Charmaz [37] characterised the study from initial coding to focused coding. Charmaz emphasises the closeness to the data, as well as an interactive process with the participants, researchers, and data. Every interview was coded line-by-line when the data were distilled and sorted. To develop categories each interview was analysed individually with subsequent comparative analysis to other interviews. Constant comparisons were made between categories and as the analysis proceeded, the categories were integrated, becoming more theoretical. Charmaz [37] argues that theoretical codes serve as interpretive frames offering an abstract understanding of relationships, which in this study resulted in a model grounded in, and abstracted from, the participants' experiences.

To assure accuracy comparisons between the data, codes, and concepts were discussed and developed within the team and were a negotiated outcome.

\section{RESULTS}

Various factors worked to create a complexity in how the participants viewed, experienced, dealt with, and valued their health. The participants mainly understood health as an emotional and a relational experience; even the bodily state and actions were interpreted through emotions. In conceptualising health the interconnection between mind and 
body was evident and health was described as a holistic concept. However, when the participants referred to their own health experiences and how they dealt with their health, they described a more dualistic view, one in which emotional and relational mind and the functional body were seen as different, yet affecting each other nonetheless.

Several factors were conducive to adolescent health and contributed in shaping the health of adolescent boys. As presented in Fig. (1), emotional and social aspects of health were strongly connected and interrelated, forming the category of the emotional and relational mind. The bodily health comprised the category of doing health as a functional condition in which the body was described as a functional tool for health.

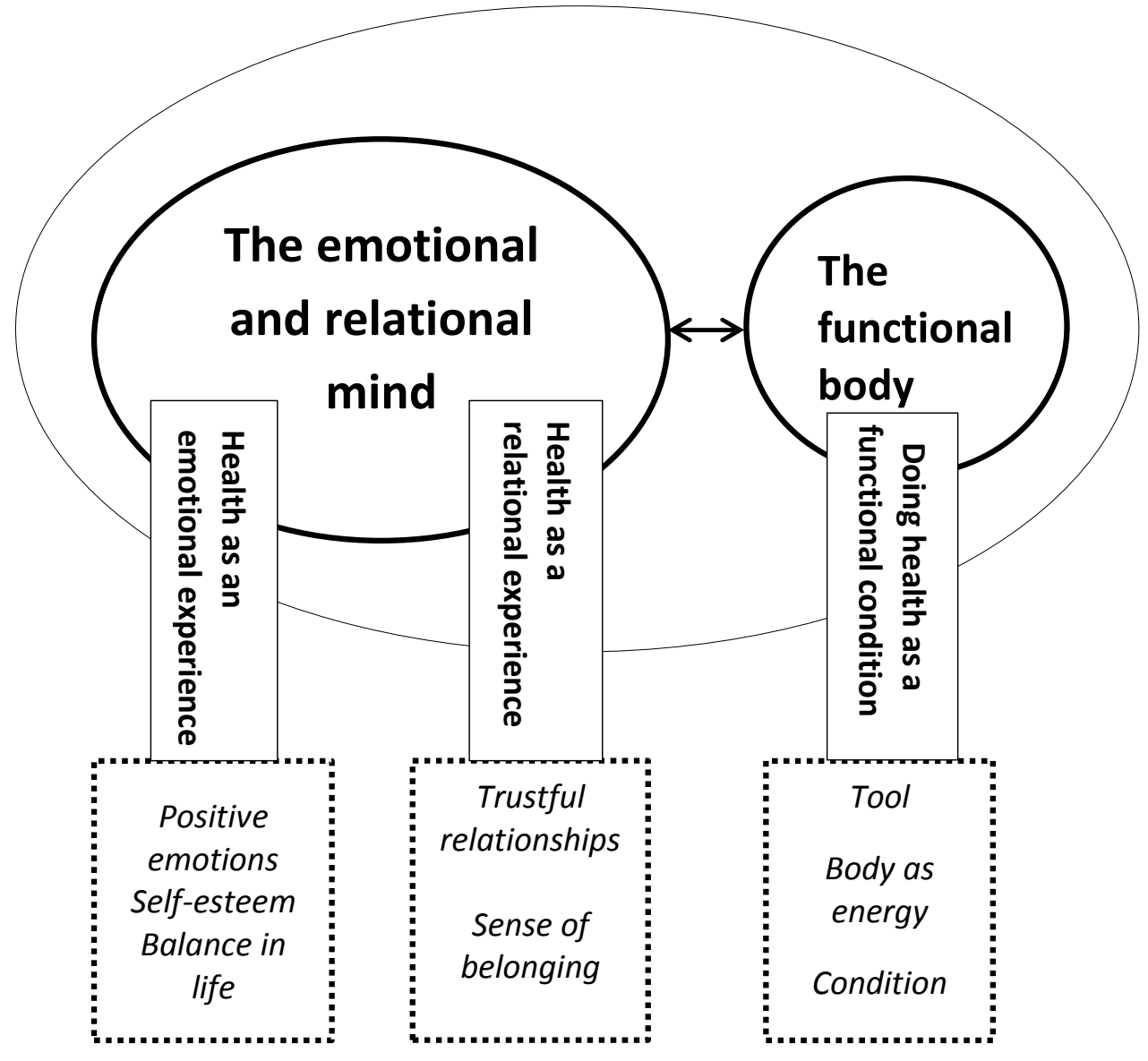

Fig. (1). Factors forming and contributing to the health of adolescent boys.

\section{Health as an Emotional Experience}

Health was considered as an emotion, that one could 'feel' health. The emotional aspects of health were underlined and three major influences to experience health as an emotion were identified.

Presence of positive emotions (e.g., happiness and freedom) and experiencing positive life events were conducive to health. When the boys described situations or periods when they experienced good health, they often used the word 'happy': "I feel good most of the time because I'm happy." Joyful happenings, good memories, having something to look forward to, and a sense of freedom, were all emphasised as sources of positive emotions. Moreover, happiness was an important goal in itself.

Second, the participants described that when they had confidence in their own abilities, they could accept who they were and sensed their own value. Further, they felt they had self-esteem, which was important for health. Concerning the importance of managing emotional health, one boy stated, "You have to first accept yourself before you can accept somebody else". A sense of enough internal resources and self-respect in relation to assessing health was regarded as highly important. In the assessment of health the subjective assessment outweighed possible objective assessments made by others. In this respect one participant described himself as being in great shape and that he exercised on a 
regular basis, but that the doctor at his school had commented several times on his weight.

If your doctor says that you're overweight and that your health is not good, it's not always the truth because you can feel great in your mind; you can have yourfamily. I think that the doctors are wrong when they say that my health is bad.

Another participant who had diagnosed diseases stated the following.

If I have good health, then I feel all right. I think that the most important thing is to feel well... I have diabetes, asthma, and allergies, but they don't affect me. I exercise a lot... although they sound like a lot, my diagnoses don't bother me.

Finally, a balance in life was essential for emotional health. Health was about finding a balance between emotions and demands and being able to cope with fluctuations in life. One of the adolescents described that he wanted to keep himself 'in between' and explained it in the following manner. "How I feel is central. I never want to be too happy or too angry. I want to be there in the middle where I can make good decisions." This view can be seen as an explicit expression of controlling emotions to preserve balance in life. Another boy explained what was needed to achieve balance.

I think that you feel well if you are satisfied with your life or what you are going to do, when school is going well, and you eat well and exercise enough-- that's health for me; and ill-heath is when you get too little or too much of everything.

Finding balance regarding stress was considered vital. The participants experienced and dealt with stress in two distinctive ways: the stress-resistant boys claimed they rarely experienced stress and if they did, they could cope with it. The stress-sensitive boys experienced extensive stress because of schoolwork, demands regarding academic performance, reading and writing difficulties, or concentration problems. These participants seemed to have difficulties in coping with their life situations, which reduced their sense of good health.

\section{Health as a Relational Experience}

Health was also experienced through interaction as relational, which consisted of relationships at home, in the immediate environment, and in the community setting. The quality of relationships and being part of a group contributed to the overall health experience.

Of vital importance for health, was the experience of trustful relationships in which the boys experienced secure relationships within the family and with close friends who could provide emotional support. The willingness to rely on somebody, share difficulties, and receive support was a matter of trust. Regarding emotional concerns, the participants who shared their problems were very careful when choosing whom they turned to. They primarily shared their problems with people who knew them very well and with those they felt they could trust. The participants emphasised that the quality (e.g., closeness, trust, and understanding) of relationships was important for sharing problems and emotions. "It is important to have friends that you can trust and to be able to talk with others". Furthermore, being seen, acknowledged, and valued by significant others were also identified as an important part of trustful relationships. One of the participants stated that what was needed to feel well was "Love and very good friends, and having people who believe in you, both in school, sports, and everything". The importance of feeling loved was stressed, as was a need to hear it verbally. "Right now I don't feel as well as I'd like to. The only thing I wish is to get recognition, not in terms of sex, but in hearing someone I like very much say, 'I love you'."

The participants also pointed out the importance of experiencing their school as a safe working environment. Friendly and helpful teachers who noticed and acknowledged them, as well as the school's efforts to combat bullying, contributed to relational safety and trust in the school as an arena for relationships.

To be a part of a group or to be connected to others, having a sense of belonging, without necessarily being deeply involved in each other's lives, was important in promoting good health. One boy said, "Guys feel good when they are part of a group". This person emphasised the importance of mutual relationships and belonging. The boys in the study saw themselves in a social context, where socialising and having access to networks were fundamental to health.

Certain lifestyle and health behaviour, such as smoking and drinking, were of a relational character and most often performed together with others as a way to strengthen a sense of belonging. Some boys smoked and some did not; some drank almost every weekend and some hardly ever. In the participants' narratives there was a total absence of 
association to health risks. The boys considered smoking and drinking as 'social tools' to increase their sense of belonging.

\section{Doing Health as a Functional Condition}

Health as a functional condition was perceived as 'doing health' in which the boys performed activities using their bodies to feel good, to achieve something, or to gain a better body image. What the boy could do with his body and his ability to perform using his body were regarded as important. The body's impact on health was described in relation to three aspects.

The body as a tool was an expression of the body being a tool to achieve what was desired for health. Some of the participants performed sports or exercised consciously, where participation in sporting activities, both indoor and outdoor, was seen as important for health. Some of the adolescents described the body as a valuable tool to manage emotions and achieve tranquillity. "I have a very bad temper but I've solved the problem thanks to sports. So, I feel good all the time when I work out regularly." Thus, to stay emotionally healthy was in part managed by exercising. However, some boys described that emotions could be dealt with by participating in challenging or risky activities, or through self-harm. One of the participants who had deliberately harmed himself stated, "I'd rather have pain in my body than pain in my mind". Other participants described the body as a tool, i.e. as an instrument that was needed to work with what they had planned. One boy emphasised the importance of taking care of the body. "If I couldn't work with my body, if I couldn't be in carpentry or exercising or participating in sports, I would be unhappy all the time ... so I try to take care of my body."

The boys also described the body as a source of energy, i.e. the body was seen as a carrier of health providing embodied energy. By performing strenuous physical activities and exercising, their energy increased, which, in turn, enhanced their mental well-being. According to one participant, "It is important to exercise because you get more energy and feel better". Being physically fit was also desired as a long-term outcome and some of the participants emphasised the importance of staying active. Thus, the adolescents described their investments in a 'future body' through being physically active at present.

Finally, the body as a condition involved a well-functioning body as an organism, as having a healthy heart, a good immune system, and sleeping and eating well: put differently, a body as a state of health and fitness worth taking care of. Some of the participants noted that the physical condition of the body affected the overall health experience. "I think that it can lower one's mental well-being if you are not physically healthy." The adolescents reported having knowledge about the intricate relationship between eating, sleeping, and health. They described that to achieve better health benefits their bodies needed enough sleep and healthy food choices. The participants also emphasised the importance of eating less junk food and taking care of their bodies, something that gave benefits but required considerable effort. As one boy said, "If you live a healthy life, it's not a sacrifice [to eat properly and exercise], but it's more exhausting to live a healthy life ... but, it's always good to live wholesomely."

\section{DISCUSSION}

Overall, our findings suggest that there was a complexity in how the participants viewed, experienced, dealt with, and valued health. In conceptualising health the boys showed awareness of the interconnection between mind and body. However, when referring to their health experiences, and particularly when dealing with health, the adolescents were prone to separate the mind from the body. There may be several reasons contributing to the distinction. The current health discourse emphasises different health dimensions, above all physical and mental, which might contribute to the consolidation of the dualistic view. In certain pressing conditions, and with regard to stress, the boys expressed a sense of being either in the body or in the mind. Alternating between being and having a body indicates a complex relationship between self and body, one in which the body is perceived both as an object and as a subject. A group of stress-resistant participants in this study seemed to keep the mind and body separated by 'switching off' stress or bodily discomfort. Recent studies on perceived stress among older adolescents show that girls report a higher level of stress and more symptoms than boys [39 - 41]. Further, some of our participants managed certain emotional stressors by switching between body and mind or by suppressing their feelings. Those boys who had experienced mental ill-health expressed a strong desire to replace an internal, unspecific pain with a visible bodily pain, which was easier to delimit and cope with. It is suggested that beliefs in mind-body dualism can serve as cognitive tools for coping [28]. Moreover, self-injury is shown to be an embodied emotion work [42]. Switching between body and mind can also be related to the expression of masculine self-control $[9,43]$. Hypothetically, the distinction of mind and body can lead to a repudiation 
of the body in favour of the mind in the context of adolescent boys. This is because the participants placed greater value on emotional and relational health as compared with physical health.

Our study indicates that what mattered most for the adolescents were the relational and emotional factors. Important for health were the presence of positive emotions, experiencing self-esteem, balance in life, trustful relationships, and having a sense of belonging. If our findings are valid, health could be depicted as primarily a relational and emotional experience, where the impact of physical health seems to be of lesser importance for adolescent boys. The body was experienced as a condition or a tool that provided energy. Accordingly, in 'doing health' the participants' ability to realise certain goals was in focus, closely connected to the action-oriented view of Nordenfelt [19]. The physical body was interpreted through social processes, judged by the ability to perform and do things, and seen as a tool or a carrier of health. Keeping the mind healthy was highly valued, with 'bodily pain' preferred to 'mental pain'. This position is in clear opposition to the Cartesian view of the body, whereby the physical body has precedence over the mental [18]. In our study physical health seemed to play a minor role, even when the participants had an illness that required daily treatment. There may be several factors affecting the superior position of emotional and relational health, but the impact of close social networks and relations seems to shape the health experience in a profound manner. Maintaining social bonds is a fundamental motive for all actions involving emotional connectedness between individuals [44]. It is also possible that physical health is viewed as a given and essential part of young health in welfare states. Consequently, it does not need as much attention as managing relationships, which requires daily attention. Eckersley [13] underlines the importance of cultural, existential, and relational factors related to adolescent health. As in our study, other studies have shown how social interaction and family and peer support are important for health and well-being [17, 45]. It is striking just how dependent the participants were on close networks, suggesting the importance of addressing social and relational health in future research.

\section{Implications for Health Care Practice}

The adolescent boys perceived health as mainly emotional or relational and were prone to dichotomise mind/body when dealing with health. Those working with youths should be particularly sensitive to the emotional and social needs of adolescent boys and encourage them to integrate physical, social, and emotional aspects of health. Schools are important social institutions for health promotion. Based on our findings, we believe that it would be highly beneficial to strengthen the sense of belonging by facilitating discussions in smaller groups, in addition to individual support services given by school nurses or school social workers [46]. By enabling shared experiences in which the relational and emotional aspects of health are acknowledged in the context of health choices and values, health improvements may be gained.

\section{Limitation and Strengths}

The study population included boys from three schools and varying backgrounds (some were well-articulated and others not). We believe that this, in combination with the sample size, increases the trustworthiness of the study [47]. Being a social worker, the principal author (ER) who conducted the interviews had extensive experience with adolescents. Furthermore, the interview questions were posed as openly as possible, which may have contributed to a safe atmosphere, and subsequently, to obtaining rich descriptions. Reflexivity throughout the research process, the iterative procedure, and the analyst triangulation, with all authors contributing to the analytical process, aimed to establish credibility and confirmability of this study $[48,49]$. However, the study was conducted in one Swedish town and the generalizability of the findings might therefore be limited.

\section{CONCLUSION}

This study provides a deeper understanding of how adolescent boys perceive health and what they experience as important for their health. There was a complexity in how health was perceived; on a conceptual level, the participants' understanding was rather holistic but when dealing with health they were prone to differentiate between body and mind in a more dualistic manner. However, health was mainly experienced as emotional and relational. For health, trustful relationships and positive emotions were valued most. The body was perceived as a tool and had a subordinate value. Findings indicating that young masculine health is largely experienced through emotions and relationships support theories on health as a social construction of interconnected processes. 


\section{AUTHORS CONTRIBUTIONS}

Study design: ER, LJ, AÖ, RF. Data collection: ER. Data analysis: ER, LJ, AÖ, RF. Writing of the manuscript: ER, LJ, AÖ, RF.

\section{CONFLICT OF INTEREST}

The authors confirm that this article content has no conflict of interest.

\section{ACKNOWLEDGEMENTS}

We wish to thank the adolescent boys who participated in the study and shared their experiences.

\section{REFERENCES}

[1] Ciarrochi J, Deane FP, Wilson CJ, Rickwood D. Adolescents who need help the most are the least likely to seek it: The relationship between low emotional competence and low intention to seek help. British J Guid Counsell 2002; 30(2): 173-88. [http://dx.doi.org/10.1080/03069880220128047]

[2] Johansson A, Brunnberg E, Eriksson C. Adolescent Girls' and Boys' Perceptions of Mental Health. J Youth Stud 2007; $10(2)$ : $183-202$. [http://dx.doi.org/10.1080/13676260601055409]

[3] MacLean A, Hunt K, Sweeting H. Symptoms of Mental Health Problems: Children's and Adolescents' Understandings and Implications for Gender Differences in Help Seeking. Child Soc 2013; 27(3): 161-73. [http://dx.doi.org/10.1111/j.1099-0860.2011.00406.x] [PMID: 26300586]

[4] Marcell AV, Ford CA, Pleck JH, Sonenstein FL. Masculine beliefs, parental communication, and male adolescents' health care use. Pediatrics 2007; 119(4): e966-75.

[http://dx.doi.org/10.1542/peds.2006-1683] [PMID: 17403834]

[5] Boyle CA, Boulet S, Schieve LA, et al. Trends in the prevalence of developmental disabilities in US children, 1997-2008. Pediatrics 2011; 127(6): 1034-42. [http://dx.doi.org/10.1542/peds.2010-2989] [PMID: 21606152]

[6] Maughan B, Rowe R, Messer J, Goodman R, Meltzer H. Conduct disorder and oppositional defiant disorder in a national sample: developmental epidemiology. J Child Psychol Psychiatry 2004; 45(3): 609-21. [http://dx.doi.org/10.1111/j.1469-7610.2004.00250.x] [PMID: 15055379]

[7] Wasserman D, Cheng Q, Jiang GX. Global suicide rates among young people aged 15-19. World Psychiatry 2005; 4(2): 114-20. [PMID: 16633527]

[8] De Visser RO, Smith JA, McDonnell EJ. 'That's not masculine': masculine capital and health-related behaviour. J Health Psychol 2009; 14(7): 1047-58

[http://dx.doi.org/10.1177/1359105309342299] [PMID: 19786531]

[9] Messerschmidt JW. "Doing Gender": The Impact and Future of a Salient Sociological Concept. Gend Soc 2009; 23(1): 85-8. [http://dx.doi.org/10.1177/0891243208326253]

[10] Connell RW. Teaching the boys: New research on masculinity, and gender strategies for schools. Teach Coll Rec 1996; 98(2): 206-35.

[11] Hagquist C. Discrepant trends in mental health complaints among younger and older adolescents in Sweden: an analysis of WHO data 1985-2005. J Adolesc Health 2010; 46(3): 258-64 [http://dx.doi.org/10.1016/j.jadohealth.2009.07.003] [PMID: 20159503]

[12] Patel V, Flisher AJ, Hetrick S, McGorry P. Mental health of young people: a global public-health challenge. Lancet 2007; 369(9569): $1302-13$.

[http://dx.doi.org/10.1016/S0140-6736(07)60368-7] [PMID: 17434406]

[13] Eckersley R. A new narrative of young people's health and well-being. J Youth Stud 2011; 14(5): 627-38. [http://dx.doi.org/10.1080/13676261.2011.565043]

[14] Jerdén L, Burell G, Stenlund H, Weinehall L, Bergström E. Gender differences and predictors of self-rated health development among Swedish adolescents. J Adolesc Health 2011; 48(2): 143-50. [http://dx.doi.org/10.1016/j.jadohealth.2010.06.005] [PMID: 21257112]

[15] Lager A, Berlin M, Heimerson I, Danielsson M. Young people's health: Health in Sweden: The National Public Health Report 2012. Scand J Pub Health 2012; 40: 42-71. [http://dx.doi.org/10.1177/1403494812459459] [PMID: 10373720]

[16] Larson JS. The conceptualization of health. Med Care Res Rev 1999; 56(2): 123-36. [http://dx.doi.org/10.1177/107755879905600201] [PMID: 10373720]

[17] Ott MA, Rosenberger JG, McBride KR, Woodcox SG. How do adolescents view health? Implications for state health policy. J Adolesc Health 2011; 48(4): 398-403 [http://dx.doi.org/10.1016/j.jadohealth.2010.07.019] [PMID: 21402270] 
[18] White K. An introduction to the sociology of health and illness. Los Angeles: SAGE 2009.

[19] Nordenfelt L. On the nature of health: an action-theoretic approach. Dordrecht: Kluwer 1995. [http://dx.doi.org/10.1007/978-94-011-0241-4]

[20] Constitution of the World Health Organization: World Health Organization 2006. Available from: http://www.who.int /governance/eb/who_constitution_en.pdf

[21] Nutbeam D. Health promotion glossary. Health Promot Int 1998; 13(4): 349-64. [http://dx.doi.org/10.1093/heapro/13.4.349]

[22] Promoting mental health: concepts, emerging evidence, practice: summary report. 20 Avenue Appia, 1211 Geneva 27; Switzerland : World Health Organization 2004.

[23] Russell RD. Social health: an attempt to clarify this dimension of well being. Int J Health Educ 1973; 16(2): 74-84.

[24] Rozemond M. Descartes's dualism. Cambridge, Mass: Harvard University Press 1998.

[25] Lengen C, Blasius J. Constructing a Swiss health space model of self-perceived health. Soc Sci Med 2007; 65(1): 80-94. [http://dx.doi.org/10.1016/j.socscimed.2007.02.053] [PMID: 17475384]

[26] McWhinney IR, Epstein RM, Freeman TR. Rethinking somatization. Ann Intern Med 1997; 126(9): $747-50$. [http://dx.doi.org/10.7326/0003-4819-126-9-199705010-00037] [PMID: 9139578]

[27] Estes D. Evidence for early dualism and a more direct path to afterlife beliefs. Behav Brain Sci 2006; 29(05): 470. [http://dx.doi.org/10.1017/S0140525X06309107]

[28] Forstmann M, Burgmer P, Mussweiler T. "The mind is willing, but the flesh is weak": the effects of mind-body dualism on health behavior. Psychol Sci 2012; 23(10): 1239-45.

[http://dx.doi.org/10.1177/0956797612442392] [PMID: 22972908]

[29] Duncan G. Mind-body dualism and the biopsychosocial model of pain: what did Descartes really say? J Med Philos 2000; $25(4)$ : 485-513. [http://dx.doi.org/10.1076/0360-5310(200008)25:4;1-A;FT485] [PMID: 10916180]

[30] Merleau-Ponty M. Phenomenology of perception. London: Routledge 1962.

[31] Engelsrud G. The lived body as experience and perspective: methodological challenges. Qualitat Res 2005; 5(3): 267-84. [http://dx.doi.org/10.1177/1468794105054455]

[32] Wilde MH. Why embodiment now? ANS Adv Nurs Sci 1999; 22(2): 25-38. [http://dx.doi.org/10.1097/00012272-199912000-00004] [PMID: 10634185]

[33] Landstedt E, Asplund K, Gillander Gådin K. Understanding adolescent mental health: the influence of social processes, doing gender and gendered power relations. Sociol Health Illn 2009; 31(7): 962-78. [http://dx.doi.org/10.1111/j.1467-9566.2009.01170.x] [PMID: 19659740]

[34] Armstrong C, Hill M, Secker J. Young people's perceptions of mental health. Child Soc 2000; 14(1): 60-72. [http://dx.doi.org/10.1111/j.1099-0860.2000.tb00151.x]

[35] Antonovsky A. The salutogenic model as a theory to guide health promotion. Health Promot Int 1996; 11(1): 11-8. [http://dx.doi.org/10.1093/heapro/11.1.11]

[36] Patton MQ. Qualitative research \& evaluation methods. London: SAGE 2004.

[37] Charmaz K. Constructing grounded theory: a practical guide through qualitative analysis. London: SAGE 2006.

[38] Glaser BG. Getting Out of the Data: Grounded Theory Conceptualization. Mill Valley, Calif.: Sociology Press 2011.

[39] Landstedt E, Gådin KG. Seventeen and stressed-Do gender and class matter? Health Sociol Rev 2012; 21(1): 82-98. [http://dx.doi.org/10.5172/hesr.2012.21.1.82]

[40] Wiklund M, Malmgren-Olsson E-B, Öhman A, Bergström E, Fjellman-Wiklund A. Subjective health complaints in older adolescents are related to perceived stress, anxiety and gender - a cross-sectional school study in Northern Sweden. BMC Public Health 2012; 12 (1): 993. [http://dx.doi.org/10.1186/1471-2458-12-993] [PMID: 23158724]

[41] Flacking R, Jerdén L, Bergström E, Starrin B. 'In or out'—on the dynamic between acceptance and rejection and its influence on health in adolescent girls. Young 2014; 22(3): 291-303. [http://dx.doi.org/10.1177/1103308814534043]

[42] Chandler A. Self-injury as embodied emotion work: Managing rationality, emotions and bodies. Sociology 2012; $46(3): 442-57$. [http://dx.doi.org/10.1177/0038038511422589]

[43] Maclean A, Sweeting H, Hunt K. 'Rules' for boys, 'guidelines' for girls: Gender differences in symptom reporting during childhood and adolescence. Soc Sci Med 2010; 70(4): 597-604. [http://dx.doi.org/10.1016/j.socscimed.2009.10.042] [PMID: 19931962]

[44] Scheff TJ. Microsociology: discourse, emotion and social structure. Chicago: University of Chicago Press 1994.

[45] Wrench A, Garrett R, King S. Guessing where the goal posts are: managing health and well-being during the transition to university studies. J Youth Stud 2012; 1-17. 
[46] Nygren K, Bergström E, Janlert U, Nygren L. Adolescent self-reported health in relation to school factors: a multilevel analysis. J Sch Nurs 2014; 30(2): 114-22.

[http://dx.doi.org/10.1177/1059840513489709] [PMID: 23674554]

[47] Graneheim UH, Lundman B. Qualitative content analysis in nursing research: concepts, procedures and measures to achieve trustworthiness. Nurse Educ Today 2004; 24(2): 105-12.

[http://dx.doi.org/10.1016/j.nedt.2003.10.001] [PMID: 14769454]

[48] Lincoln YS, Guba EG. Naturalistic inquiry. Beverly Hills, Calif.: Sage 1985.

[49] Malterud K. Qualitative research: standards, challenges, and guidelines. Lancet 2001; 358(9280): 483-8. [http://dx.doi.org/10.1016/S0140-6736(01)05627-6] [PMID: 11513933]

C Randell et al.; Licensee Bentham Open.

This is an open access article licensed under the terms of the Creative Commons Attribution-Non-Commercial 4.0 International Public License (CC BY-NC 4.0) (https://creativecommons.org/licenses/by-nc/4.0/legalcode), which permits unrestricted, non-commercial use, distribution and reproduction in any medium, provided the work is properly cited. 